\title{
The integrated safety supervision and emergency platform of urban rail transit construction
}

\author{
Ming Zhang \\ Institute of Computing Technologies, China Academy of Railway Sciences, Beijing \\ 100081, China \\ Email:zm_zhangming@hotmail.com
}

\begin{abstract}
The paper proposes a framework for safety monitoring and emergency platform by means of analyzing the demand for sharing information on control and management as well as the measures taken in safety guarantee system from the perspective of importance of safety in constructing urban rail transit. It analyzes the functions in a detailed way concentrating on such main business as risk supervision, shielding deviation monitoring and inspection of potential problems in safety and quality along with the emergency response to accidents. The core technologies are set up related to established plans automatically for multi-major debugging of facilities and data fusion on monitoring and early warning. It shows its effectiveness in capturing risks and employing pre-alarm data for decision-making and safety management through actual application in engineering.

Keywords: Urban Rail Transit; Construction Safety; Risk Supervision; Data Fusion.
\end{abstract}

\section{Introduction}

In recent years, Urban Rail Transit (URT) is rapidly growing in China, and there are 89 metro lines are building closed to 2500 miles. Its construction covers three stages: civil engineering, train running test, and operation on trial. Large range of project and persisting building arouse risks and security problems, so the safety system is necessary for enterprise. This paper establishes a safety supervision and emergency platform of construction, in order to quickly collect information and provide an effective solution for safety management, through risk monitors and hidden danger check. Also, the emergency technical strategies are scientifically worked out and rapidly respondent while accident happened. 


\section{Requirement of Information Sharing for Safety}

(1) During the construction in URT project, the characters of scattered sites, multiple participant units, low efficiency of large data analysis for pre-alarm may lead to safety management difficulty. Also, the evaluation for risk factors and reasonable disposal need sufficient information resource [1].

(2) After fixing equipment and single unit testing, it will enter the phase of trial train testing that serves as an integrated test to examine the vehicles and facility reach their design request, and it is an important process to assess the lines can be put into running. Owing to frequently crossing tasks and involving multiple majors, the common occupancy in time and space become contradictory for binding sites. Then we figure out a series of testing plan for them.

(3) In the phase of trial running, the situation and alarms are collected, such as vehicles, signals, ventilation and air conditioning, drainage, power supply and low voltage distribution, communication, fire detectors, the escalator, automatic fare collection, from the supervision systems. On the basis of relevant indexes calculation and statistics like failure rate, we can evaluate construction effect, the quality of equipment by suppliers to make blacklist. Thus, the integrated systems of trains and lines can be put into stable and security status rapidly.

\section{The Structure of Safety Supervision and Emergency Platform}

The platform of Safety Supervision and Emergency (SSE) of URT is designed to manage and control of construction process, including the data collection, risk inspection, evaluation analysis, emergency treatment and information sharing.

\subsection{Safety supervision system in construction}

The main points in construction management are risk inspection, shield pan offset monitoring, investigation of quality danger, which can be obtained by record analysis, e.g. detectors, shield machine parameters, video surveillance.

(1) Security risk supervision

The main function includes geography and geology information analysis, monitoring data comparison, inspection report, and risk resource list.

(2) Deviation monitoring of shield construction

Shield construction management mainly concentrates on analysis of the shield from the professional point of view [2]. The collected data returned from the shield machine is submitted into SSE platform to calibrate the parameters through with filtering the data units, to assess the safety and correctness. 
(3) Investigation of safety and quality hidden danger

Take the construction project, decoration, installation, and quality as the control objects, the platform sets key points for investigation [3, 4]. Moreover, monitoring objects usually cover relevant department of the site, also put into special investigation of quality hidden trouble for assessment and elimination.

Thus, according to the demand of the whole process safety management, the platform can meet for the construction participants' non-timed access, it further collects equipment situation and abstracts emergency information and feedback.

\subsection{Platform functions}

The platform screen security situation for all process of construction, and provide all sorts of information to support inspection. When the accident happened, it can dispatch rescue resource and command by searching and dissemination tasks to coordination $[5,6]$. Especially, the data sharing system is designed to gather real-time and non-real time data as the foundation.

(1) Debugging plan establishment

Besides the supervision and pre-alarm, mainly on period of systems testing, trial operation, video is collected and unified for statistics. In the monitoring screen, we can see both the normal status of train running with equipment mode and the fault alarm in the real time. Moreover, the debugging plans for every major monitor systems are established based on history data.

(2) Emergency management

The platform provides functions of duty, rescue resources, plan management, accident report, and treatment summarizing, all process of emergency response covered. Furthermore, geographic information system is employed to build special layers for construction lines, based on space database of corresponding city, which is not only applied to map search, but also supports risk positioning, alarm display, location query of rescue resources, and visional command.

\section{Core Technologies of the Platform}

\subsection{Comprehensive early warning of construction detection}

(1) Construction risk warning

The detection and standard value are compared to determine unsafe extent. According to close to or exceed, the alarm is divided into 3 levels. The patrol early warning points to the project itself or the surrounding environment due to potential risks or unsafe state, through on-site inspections and process analysis. 
(2) Shield management

It includes shield interval, shield machine location, and attributes. The main parameters is generalized as follows: work situation, soil pressure, cutter head torque, synchronous grouting, offset of $\mathrm{X}$ and $\mathrm{Y}$ from center of the cutter head.

(3) Hidden danger warning

The hidden danger here means unsafe condition, which is the direct cause of accident, such as bolt fracture, solder joint welding, and high concentration of harmful gas. According to casualties, losses, social impact and its probability of occurrence, the risk is divided into 4 levels with severity decreased.

\subsection{Method of trial train plan establishment}

In order to reasonably arrange these test and avoid conflict when execute simultaneously in the same station interval, the united debugging plan is built, not simple combination of single plans. Therefore, we design the conflict detection algorithm to realize scheduled debugging plan. Define conflict detection model and generalize main factors as six tuple as, including debugging major, subsystem, orders, pre-condition, force or weak electricity, and plan time stamp. In detail, $M$ means all sorts of major. $S$ means the least unit debugging subsystem. $O$ means relation among the single plans. $C$ means basic conditions after preceding debugging and before the next. $W$ points to debugging with power like train running and mechanical test. $T\left(t_{i}, t_{i+1}\right)$ covers the begin and finish time of major $M_{i}$. Define the time range is $\left[T_{a}, T_{b}\right]$, and any test task should be carried out within it. $\forall i \in Q, T_{a} \leq T_{i} \leq T_{b}$. Every task can be described as $\operatorname{plan}_{\text {sub }_{i}}\left(\Delta t_{j}\right)$, and their pre-conditions is presented as:

If $C_{s u b_{i}}\left(t_{i}\right)+\operatorname{plan}_{s u b_{j}}\left(\Delta t_{j}\right) \leq C_{s u b_{i+1}}\left(t_{i+1}\right)$, then $C_{s u b_{i}}$ is regarded as precondition $C_{s u b_{i+1}}$. If $T_{s u b_{i}}\left(t_{i}^{a}\right) \neq T_{s u b_{j}}\left(t_{j}^{a}\right)$, then means the task $i$ is conflict with task $j$. It points to the two tasks cannot be executed at same time or same space, and the debugging time should be committed in the maintenance period while out of operation time. It also includes constraint as $t_{i}^{a} \leq \operatorname{plan}_{s u b_{j}}\left(\Delta t_{j}\right) \leq t_{i+1}^{b}$. Thus, the integral plan will be obtained based on multiple major optimization, as in Eq. (1).

$$
\min \sum_{i=1}^{n}\left[T_{\text {sub }}^{a}\left(t_{i}\right)+\operatorname{plan}_{\text {sub }}\left(\Delta t_{i}\right)\right]
$$

The plan is firstly set to start time, end time of the schedule within time limits, and assume that every task can be completed in current debugging. Those orders are described mechanical and electrical system shall be carried out after 
the power system test, and the test of communication and power system shall be carried out after the transmission system debugging finished.

Generally, the plan automatically calculated by the algorithm is different from the initial debugging plan established by each major operator. Thus, in order to make the plan more practical and workable, synchronous adjustment of professional programs is loaded according to critical time node of integral plan.

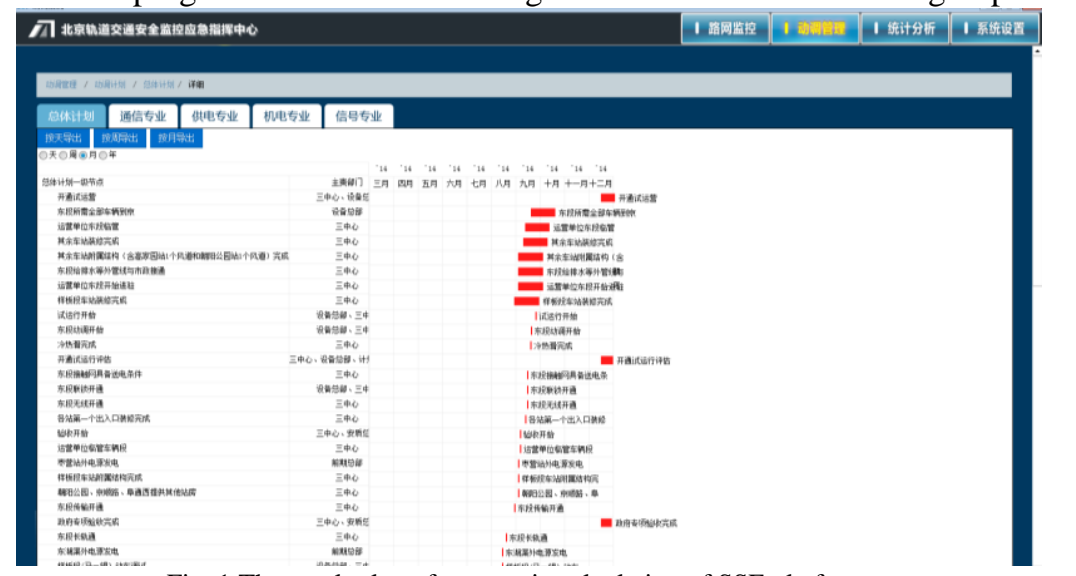

Fig. 1 The result plan of automatic calculation of SSE platform

\subsection{Data fusion of construction safety monitoring}

Considering the uncertainty of data collection from different sources, it is difficult to judge relevant meanings of the evidence on different targets. It is necessary to apply the knowledge base and data mining methods to reduce and alleviate non-controllable deviation. We took 6 months monitoring data in SSE of Beijing metro as an example. The analysis shows majority of monitors focusing on state are in level 2 and 3, without level 1 and 4, which means this supervision is essential to avoid more dangers in time. The risk is distributed in grade 2 and 3, but the total is apparently low. Moreover, four types of hidden danger are totaled to identify their relations. The details are shown as follows.

Tab. 1 Total of monitoring numbers

\begin{tabular}{lll}
\hline Monitoring type & Grade & Total \\
\hline safety state of & level 2 & 496 \\
supervision & level 3 & 3469 \\
\multirow{2}{*}{ detection point of risk } & warning 2 & 9 \\
& warning 3 & 34 \\
\hline
\end{tabular}




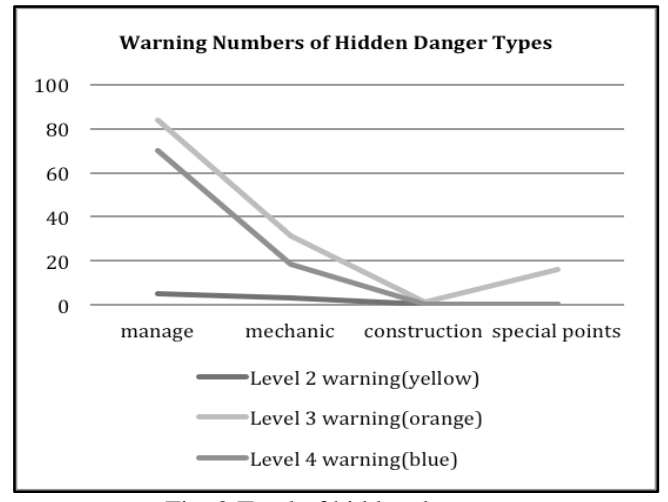

Fig. 2 Total of hidden dangers

Based on the result, we find that the number of hidden danger in construction is least, which shows good quality in building project in the period of these 6 months. More pre-alarms from mechanic systems reach level 3, and it will be threaten for debugging correlation. Besides these objective monitoring, there are many mange factors related to warning especially in level 3 and 4. Although the check index of mange has uncertainty, the solution will be the next focus.

\subsection{Intelligent decision technology application}

To establish a command decision model, the core step is to select and figure out a disposal process, called "information fusion, situation assessment, decision making and response implementation". Uncertainty of information fusion includes the real-time nature of the information, the ability and scope of monitoring equipment, various types of information synchronization, and the time delay of feedback [7]. The derivation and disposition of the probability method, using the same and similar environmental events occurred, are more representative for the correction of the preliminary decision.

\section{Conclusion}

The safety supervision and emergency platform provides a unified platform for the safety management and accident response of URT construction. This project has been put into implementation in many urban rail transit in China, the operation results show that it can effectively assist decision-making management to secure the construction safety situation and effect evaluation, and further improve emergency rescue ability. 


\section{References}

1. M. Yu, Z.Y. He, Q.Q. Qian. Reliability analysis on integrated supervision \& control system in Metro based on HSRN. Journal of the China railway society, Vol. 34(2), (2012, China), pp. 70-79.

2. D.W. Qiu, S.L. Yang. Research on the monitoring system of construction for urban subway. Science of Survey and Mapping, Vol. 32(4), (2007, China), pp. 175-200.

3. A Oberhauser, A Leitner, C Nebois, et al. Monitoring and Safety Management of Tunnels in the Vienna Metro Network. ISRM Regional Symposium - EUROCK (2015, Salzburg, Austria).

4. Q.K. Wang, S.Q. Wang, C.Wan, et al. Development of construction safety monitoring management information system for urban rail transit. Journal of WuHan University of Technology, Vol. 7, (2010, China), pp. 147-151.

5. F.B. Wu, H. Jin, Y.J. Shang, et al. The environmental risk assessment of urban rail transit. Chinese Journal of Underground Space and Engineering, Vol. 6(3), (2010, China), pp. 640-644.

6. G.G.Feng. Information construction of urban rail transit construction quality and safety management program design. Journal of Safety Science and Technology, Vol. 8(12), (2012, China), pp. 74-79.

7. Jensen. Safety efforts on large construction projects - the Copenhagen Metro. Modernización Empresarial En El Perú, (2003). 